\title{
Synthesis of an Oxathiolane Drug Substance Intermediate Guided by Constraint Driven Innovation
}

\author{
K. Kashinath, $\ddagger$ David R. Snead, $¥ *$ Justina M. Burns, Rodger W. Stringham, B. Frank Gupton, D. Tyler \\ McQuade*
}

Supporting Information Placeholder

\begin{abstract}
A new route was developed for construction of the oxathiolane intermediate used in the synthesis of lamivudine (3TC) and emtricitabine (FTC). We developed the presented route by constraining ourselves to low cost, widely available starting materials - we refer to this as supply centered synthesis. Sulfenyl chloride chemistry was used to construct the framework for the oxathiolane from acyclic precurors. This bond construction choice enabled the use of chloroacetic acid, vinyl acetate, sodium thiosulfate and water to produce the oxathiolane.
\end{abstract}

Lamivudine 1, and emtricitabine 2, are essential components of widely prescribed multi-drug regimens. ${ }^{1}$ Both nucleosides analogs are high dosage/high demand drugs and manufactured in large volumes (>1000 MT/yr). Though the price of 3TC $(\sim \$ 140 / \mathrm{kg})$ is low by comparison to other APIs of similar structural complexity, procurers (GOs and NGOs) spend $>\$ 200 \mathrm{MM} /$ year and the number of patients that receive these life-saving medicines is fixed by procurer budgets. For this reason, decreasing production costs constitutes an impactful yet difficult challenge.

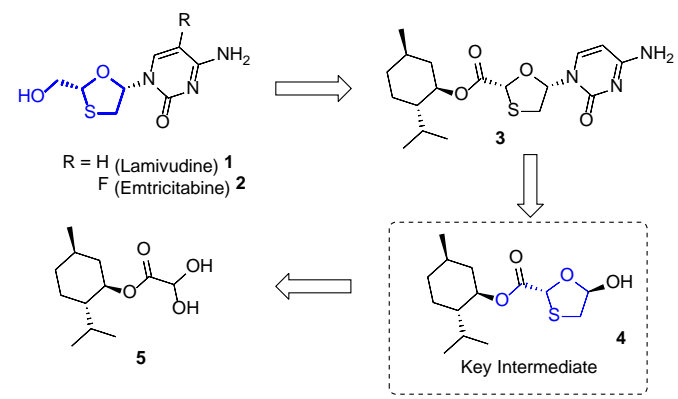

Figure 1. Commercial synthetic route for lamivudine and emtricitabine.

The vast majority of innovation related to 3TC and FTC has focused on improved methods to establish stereochemistry about the oxathiolane ring ${ }^{2}$ and install the cytosine nucleobase. ${ }^{2 \mathrm{a}, \mathrm{h}, \mathrm{k}, 3}$ Despite these efforts, the original synthesis developed at GSK by Whitehead and coworkers remains in place today as the manufacturing bond forming sequence of choice (Figure 1). ${ }^{2 \mathrm{i}, \mathrm{k}}$ The GSK approach features a dynamic kinetic resolution to afford optically pure hydroxyoxathiolane 4, a key intermediate in the synthesis. Menthol 6 controls the stereochemical outcome of the DKR which is driven to completion via selective crystallization of a single isomer from solution.
Perhaps a different way to approach the problem would be to work within the current manufacturing route. One such strategy would be to improve the route to oxathiolanes themselves thus complementing the existing knowledge, supply chain, and regulatory framework. The majority of syntheses make use of condensation of 1,4-dithiane-2,5-diol with an aldehyde, with an exception presented in the step-wise ring closing of a protected hemi-thioacetal by Rayner and coworkers also at GSK. ${ }^{2 f}$ We hypothesized that a new approach that replaced the use of the glyoxylate ester and the dithiane-diol could accomplish three outcomes: (1) decrease the raw material costs; (2) increase the supply-chain security for making 3TC and FTC; and (3) increase the number of producers because an entirely new approach might fit well in to the skill set of new market entrants.

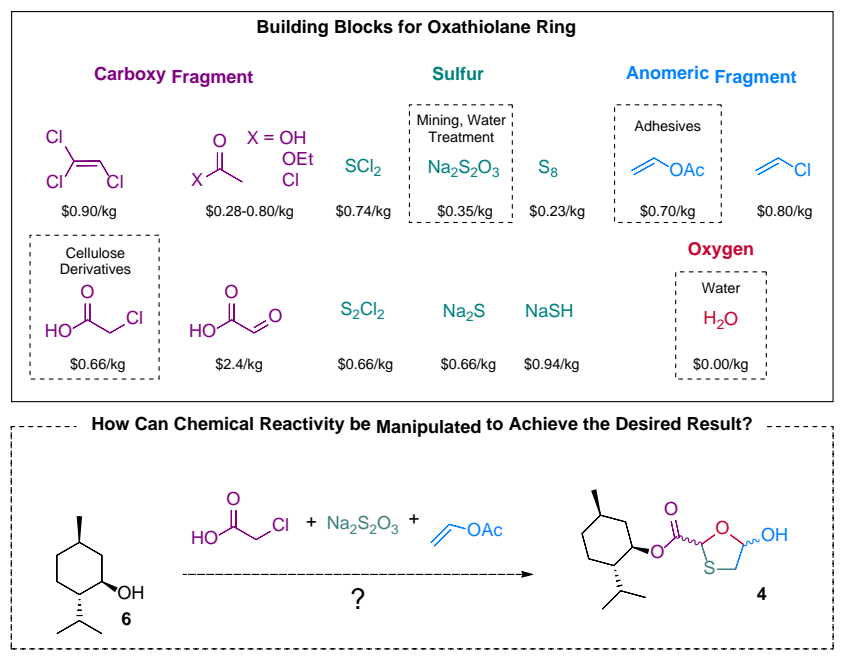

Figure 2. Supply centered synthesis molecular construction from commodity chemical materials.

Our team at M4All starts designing new routes from the perspective that APIs can be built from simple, high-volume, low-cost raw materials using modern synthetic methods/knowledge. We call this approach "Supply Centered-Synthesis". To envision new economical routes to oxathiolanes, we developed a subset of building blocks with the right oxidation state, functionality, and carbon count for each fragment of the ring (Figure 2). Viability of each building block was assessed by examining volume and price of each chemical as found through import/export records of India, a major player in the global manufacture of API. Instead of consid- 
ering the most straightforward retrosynthetic assembly of fragments, we prioritized reagent availability and cost and then sought reactions to render a viable process.

Chloroacetic acid, sodium thiosulfate and vinyl acetate quickly emerged as lead candidates, presuming they could be transformed into the oxathiolane core in a modest number of steps. All of these

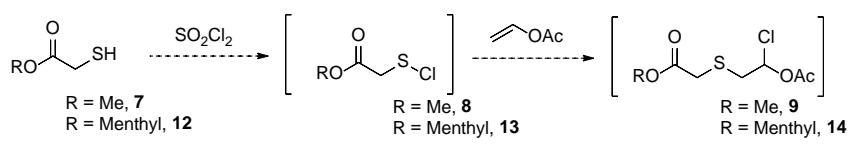

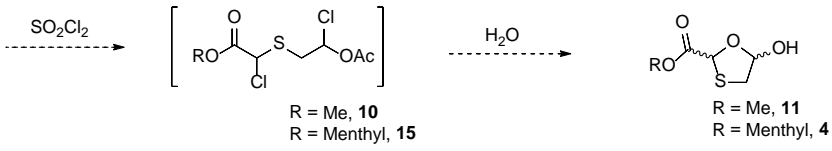

Figure 3. Proposed route to oxathiolane from vinyl acetate and glycolate ester.

raw materials are fundamental feedstocks for the chemical industry and are $<\$ 1 / \mathrm{kg}$. Their end uses point toward their high volume consumption: chloroacetic acid is used to make cellulose derivatives for the food and cosmetics industry, sodium thiosulfate is used in mining, water treatment and fertilizer industries, and vinyl acetate is used as the precursor to polyvinyl acetate, a major adhesive class. Since these are produced in the 100's of MM kg/yr, the supply chain and availability is secure. While starting from low cost, highvolume raw materials is somewhat obvious, the key to their use is development of an efficient route. Five bonds must be constructed, three oxidations are needed, and one functional group must be hydrolyzed. Although many routes were considered by our team, we found the route in Figure 3 to be the most promising.

The route we envisioned starts with chlorination of thioglycolic acid using the method of Smit (Figure 3). ${ }^{4}$ If we wanted to take the process to very high volume starting materials, thioglycolic acid can be accessed from chloroacetic acid and sodium thiosulfate. ${ }^{5} \mathrm{We}$ imagined that the sulfur-carbon bond could result via regioselective 1,2-insertion of a sulfenyl chloride into the olefin of vinyl acetate to directly couple the two carbon containing fragments. ${ }^{6}$ In this way, the required oxidation state at the anomeric center, a masked aldehyde, could be established. Futhermore, we hypothesized that excess sulfuryl chloride could $\alpha$-chlorinate the ester thereby establishing all of the necessary oxidations states. ${ }^{7}$ Reaction with water to close the ring would complete the oxathiolane synthesis.

${ }_{\mathrm{RO}} \stackrel{\mathrm{O}}{\mathrm{SH}}+\mathrm{T}_{\mathrm{OAC}} \stackrel{\text { 1) } \mathrm{SO}_{2} \mathrm{Cl}_{2}, \mathrm{DCM}, \mathrm{rt}, 30 \mathrm{~min}}{\longrightarrow}$

Table 1: Oxidative coupling of thioglycolic acid and vinyl acetate

\begin{tabular}{|c|c|c|c|c|c|}
\hline Entry & $\mathbf{R}$ & $\begin{array}{l}\text { Order of } \\
\text { Addition }\end{array}$ & $\begin{array}{c}\text { Volumes } \\
\text { Solvent }\end{array}$ & Temp. $\left({ }^{\circ} \mathrm{C}\right)$ & Yield (\%) \\
\hline $1^{\mathrm{a}, \mathrm{c}}$ & $\mathrm{Me}$ & VA Last & $10 x$ & 20 & 76 \\
\hline $2^{b, c}$ & $\mathrm{Me}$ & $"$ & $"$ & " & 91 \\
\hline $3^{\mathrm{b}, \mathrm{d}}$ & $\mathrm{Me}$ & $\begin{array}{c}\mathrm{SO}_{2} \mathrm{Cl}_{2} \\
\text { Last }\end{array}$ & $"$ & $"$ & 90 \\
\hline $5^{\mathrm{b}, \mathrm{e}}$ & $\mathrm{Me}$ & MTG Last & $"$ & $"$ & 89 \\
\hline $6^{\mathrm{b}, \mathrm{c}}$ & $\mathrm{Me}$ & VA Last & $2 \mathrm{x}$ & $"$ & 83 \\
\hline $7^{\mathrm{b}, \mathrm{c}}$ & $\mathrm{Me}$ & $"$ & $6 x$ & $"$ & 91 \\
\hline $8^{\mathrm{b}, \mathrm{c}}$ & $\mathrm{Me}$ & $"$ & $10 \mathrm{x}$ & $"$ & 91 \\
\hline $9^{b, c}$ & $\mathrm{Me}$ & " & $2 \mathrm{x}$ & -20 & 90 \\
\hline $10^{\mathrm{b}, \mathrm{c}}$ & $\mathrm{Me}$ & $"$ & $6 x$ & $"$ & 97 \\
\hline $11^{\mathrm{b}, \mathrm{c}}$ & $\mathrm{Me}$ & $"$ & $10 \mathrm{x}$ & $"$ & 95 \\
\hline $12^{\mathrm{b}, \mathrm{f}}$ & Menthyl & $"$ & $6 x$ & $"$ & 99 \\
\hline $13^{\mathrm{g}}$ & Menthyl & $"$ & $"$ & $"$ & 95 \\
\hline
\end{tabular}

a) Reaction run in $4 \mathrm{~mL}$ vial open to atmosphere. b) Reaction run in sealed NMR tube. c) Vinyl acetate added to mixture of MTG and $\mathrm{SO}_{2} \mathrm{Cl}_{2}$. d) $\mathrm{SO}_{2} \mathrm{Cl}_{2}$ added to a mixture of MTG and vinyl acetate. e) MTG added to a mixture of vinyl acetate and $\mathrm{SO}_{2} \mathrm{Cl}_{2}$. f) Reaction run in $\mathrm{CDCl}_{3}$. g) Reaction run in toluene.

The key transformation was validated by combining methyl thioglycolate (MTG, 7) and vinyl acetate (VA) (Table 1). Optimization increased the yield of the dichlorinated intermediate $\mathbf{1 0}$ to $>95 \%$. The model system was quickly extended to the menthyl ester with performance matching that of the methyl ester, and the reaction was conducted in toluene for increased sustainability.

We observed an unanticipated feature of the reaction early on where reactions run in sealed vessels provided much higher yields compared to reactions run in open vessels (Entries 1 and 2). When sealed reactions were opened, gas release was evident. Further, in a pressurized NMR tube, $\mathrm{HCl}$ reacted with vinyl acetate to make 1chloroethyl acetate. The reaction appears to be sensitive to the $\mathrm{HCl}$ gas concentration in solution and we suspect that this is the origin of the pressure dependence.

The reaction also showed a strong temperature dependence. Lowering reaction temperature increased yield significantly (Entries 68 vs. 9-11). A large exotherm was observed both on addition of sulfuryl chloride and vinyl acetate. Presumably cooling helps to mitigate the detrimental effects of the exotherm. Reactions run at room temperature rather than $-20{ }^{\circ} \mathrm{C}$ contained primarily monochlorinated sulfide $\mathbf{9}$ as a major impurity, a surprising result of incomplete reaction. One would expect a system to be overly reactive at elevated temperatures. Perhaps the reason for this phenomenon is similar to that of the observed pressure sensitivity. There is a need to maintain headspace control and keep gases in solution; however, gases become less soluble as temperature increases. Sulfuryl chloride is stated to behave as a source of chlorine gas, a compound which is known to promote $\alpha$-chlorination. ${ }^{8}$ Possibly $\mathrm{HCl}$ or $\mathrm{Cl}_{2}$ is the required for the transformation to take place, and temperature rise might drive these out of the system. This is consistent with decrease in yield as reaction concentration increases-tight temperature control is more difficult to maintain.

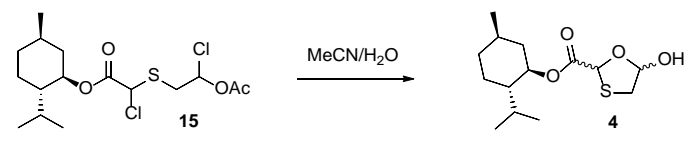

Table 2. Optimization of Ring Closing in Water

\begin{tabular}{|c|c|c|c|c|c|}
\hline Entry & $\begin{array}{c}\mathrm{MeCN}: \\
\mathrm{H}_{2} \mathrm{O}^{\mathrm{a}}\end{array}$ & $\begin{array}{c}\text { Temp } \\
\left({ }^{\circ} \mathrm{C}\right)\end{array}$ & Additive & $\begin{array}{l}\text { Time } \\
\text { (hr) }\end{array}$ & $\begin{array}{c}\text { Yield } \\
\text { (\%) }\end{array}$ \\
\hline $1^{\mathrm{c}}$ & 1.5 & 65 & - & 15 & 42 \\
\hline $2^{\mathrm{b}}$ & 2 & 55 & $\mathrm{NaOAc}$ & 15 & 48 \\
\hline $3^{\mathrm{b}, \mathrm{d}}$ & 2 & 55 & TEA & 22 & 69 \\
\hline $4^{\mathrm{b}, \mathrm{d}}$ & 1 & 80 & $\begin{array}{c}\text { 1M TEA in } \\
\text { ACN }\end{array}$ & 2 & 64 \\
\hline $5^{b, d}$ & 1 & 80 & $1 \mathrm{M} \mathrm{NaHCO}_{3}$ & 2 & 68 \\
\hline $6^{c}$ & 1 & 60 & $\alpha$-pinene & 8 & 63 \\
\hline $7^{c}$ & 1 & 80 & $\alpha$-pinene & 3 & 66 \\
\hline $8^{c}$ & 1 & 100 & $\alpha$-pinene & 2 & 69 \\
\hline $9^{c}$ & 1 & 90 & Styrene oxide & 2.5 & 66 \\
\hline $10^{c}$ & 1 & 90 & $\begin{array}{l}\text { 2,2-Dimethyl } \\
\text { oxirane }\end{array}$ & 2.5 & 62 \\
\hline
\end{tabular}

a) 20 volumes of acetonitrile b) Reaction run at $100 \mathrm{mg}$ scale c) Reaction run at $1 \mathrm{~g}$ scale. d) Additive was added portion wise. 
Proof of concept for the process was completed by demonstrating viability of ring closing to form the oxathiolane from 15 (Table 2). Combining 15 with water and acetonitrile provided the desired material in a modest $42 \%$ yield and with optimization the yield was improved to 69\%. During optimization, we discovered that highest yields were obtained when the ring closure was run between $\mathrm{pH} 3$ 4 using base additions to maintain the $\mathrm{pH}$ within those constraints. We propose that the reaction proceeds first through hydrolysis of the acetate, to generate aldehyde. The $\alpha$-chloride is then hydrolyzed and the ring closes. Controlling $\mathrm{pH}$ to neutralize $\mathrm{HCl}$ generated in the course of reaction led to slight improvement in yield, but it was important not to reach alkaline $\mathrm{pH}$ as base rapidly decomposes starting material and product.

This route depends on access to menthyl ester 12. Fortunately, esterification of thioglycolic acid provided entry to this compound in high yield (98\%). ${ }^{9}$ Only trace solvent ( 0.5 volumes of toluene) was needed for the sake of temperature control and removal of water to drive the esterification. (Figure 4).
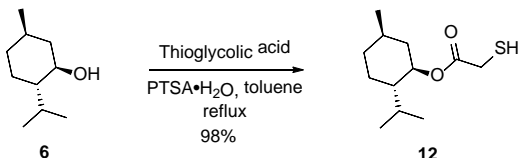

Figure 4: Esterification of menthol.

The individual transformations were stitched together to take menthol directly to oxathiolane intermediate $\mathbf{4}$ needing only a water rinse prior to isolation by crystallization (Figure 5). $10 \mathrm{~g}$ of menthol was reacted with thioglycolic acid in 5 volumes of toluene. After 2 hours, the reaction was cooled to $0{ }^{\circ} \mathrm{C}$ and sulfuryl chloride was added to ester $\mathbf{1 2}$ to afford sulfenyl chloride 13. The reaction was further cooled to $-20^{\circ} \mathrm{C}$ before adding vinyl acetate. Reagents were added over 15 minutes by syringe pump due to the large exotherms. The reaction mixture was partially quenched with sodium bicarbonate and the toluene was stripped from chlorinated residue. Acetonitrile and water were added to after returning the chlorinated intermediate $\mathbf{1 5}$ to a reaction flask. Heating at $70{ }^{\circ} \mathrm{C}$ formed the oxathiolane which was isolated by extraction with toluene and crystallizing with hexanes as antisolvent in $56 \%$ overall yield. Compound $\mathbf{4}$ was converted to lamivudine 1 with $99 \%$ chiral purity by following known procedure. ${ }^{2 \mathrm{i}}$

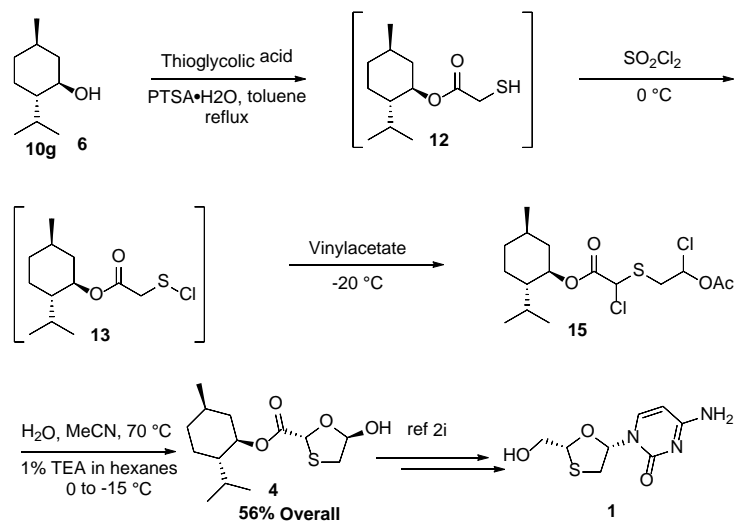

Figure 5: Synthesis of $\mathbf{4}$ directly from menthol.

We investigated a wide range of conditions to improve the yield of the cyclization from $\mathbf{1 5}$ to $\mathbf{4}$. The modest yield of product is accompanied by off-products that appeared as broad signals by NMR and were not observed using HPLC or other characterization technique. We speculate that either $\mathbf{1 5}$ decomposes to materials that evaporate readily or oligomerize. Because our attempts at byproduct analysis did not provide actionable insights, we explored the system in more detail by replacing vinyl acetate with ethyl vinyl ether. Our hypothesis was that swapping the acetate with an ethyl would alter the reaction coordinates. Unexpectedly, the aldehyde was obtained upon working up the addition of sulfenyl chloride to olefin rather than the chloroether. Overall yield increased moderately after cyclization, but more importantly, the solvent quantity required for cyclization is reduced by half as compared to vinyl acetate approach. ${ }^{10}$ Alkyl chlorides are quite hydrophobic, and presumably the reduced need for solvent is an effect of cleaving one of the alkyl chlorides.

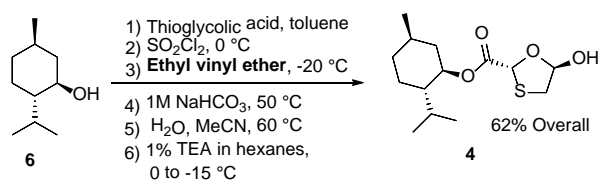

Figure 6: One-pot synthesis of $\mathbf{1}$ from menthol and ethyl vinyl ether.

In this way, the sulfenyl chloride methodology proved to be a versatile platform for entry into oxathiolane chemistry. Relevant thiol esters were made from thioglycolic acid. The resultant thiol was halogenated with sulfuryl chloride, and this sulfenyl chloride was used to construct a sulfur carbon bond with vinyl acetate and ethers. Presence of excess sulfuryl chloride halogenated the ester in the $\alpha$ position. This dichlorinated intermediate was cyclized in water to generate the oxathiolane used in synthesis of 3TC and FTC. By focusing on the chemical industry's supply chain and base reagents, a novel route was tailored to fit starting materials. Combining a target-oriented retrosynthetic perspective with a supply centered viewpoint served as a useful constraint to generate creative and novel solutions for longstanding challenges.

\section{ASSOCIATED CONTENT}

\section{Supporting Information}

The Supporting Information is available free of charge on the ACS Publications website including experimental details.

\section{AUTHOR INFORMATION}

\author{
Corresponding Author \\ * David Snead \\ Medicines for All Institute \\ 737 N 5th St. \\ Box 980100 \\ Richmond, Virginia 23298 \\ E-mail: drsnead@vcu.edu \\ * D. Tyler McQuade \\ Medicines for All Institute \\ 737 N 5th St. \\ Box 980100 \\ Richmond, Virginia 23298 \\ E-mail: tmcquade@vcu.edu
}

\section{Author Contributions}

$\ddagger$ These authors contributed equally.

\section{Notes}

The authors declare no competing financial interests.

\section{ACKNOWLEDGMENT}

We thank the Bill and Melinda Gates Foundation for their longstanding support of our research. 


\section{REFERENCES}

1) Panos, Z.; Fox, J.; Prabhu, V. “HIV Market Report” from Clinton Health Access Initiative, 2019, 10. Accessed Feb. 6, 2020 at: http://clintonhealthaccess.org/wp-content/uploads/2019/12/2019HIV-Market-Report.pdf

2) a) Humber, D.C.; Jones, M.F.; Payne, J.J.; Ramsay, M.V.J.; Zacharie, B.; Jin, H.; Siddiqui, A.; Evans, C.A.; Tse, H.L.A.; Mansour, T.S. Expeditious preparation of (-)-2'-deoxy-3'-thiacytidine (3TC), Tetrahedron Lett., 1992, 33, 4625-4628. b) Hoong, L.K.; Strange, L.E.; Liotta, D.C.; Koszalka, G.W.; Burns, C.L.; Schinazi, R.F. Enzyme-mediated enantioselective preparation of pure enantiomers of the antiviral agent 2',3'-dideoxy-5-fluoro-3'thiacytidine (FTC) and related compounds, J. Org. Chem., 1992, 57, 5563-5565. c) Jeong, L.S.; Schinazi, R.F.; Beach, W.J.; Kim, H.O.; Nampallia, S.; Shanmuganathan, K.; Alves, A.J.; McMillan, A.; Chu, C.K.; Mathis, R. Asymmetric synthesis and biological evaluation of $\beta$-L-(2R,5S)- and $\alpha$-L-(2R,5R)-1,3-oxathiolane-pyrimidine and -purine nucleosides as potential anti-HIV agents, $J$. Med. Chem., 1993, 36, 181-195. d) Mahmoudian, M.; Baines, B.S.; Drake, C.S.; Hale, R.S.; Jones, P.; Piercey, J.E.; Montgomery, D.S.; Purvis, I.J.; Storer, R.; Dawson, M.J.; Lawrence, G.C. Enzymatic production of optically pure ( $2^{\prime} \mathrm{R}$-cis)-2'-deoxy-3'-thiacytidine (3TC, lamivudine): A potent anti-HIV agent, Enzyme Microb. Technol., 1993, 15, 749-755. e) Milton, J.; Brand, S.; Jones, M.F.; Rayner, C.M. Enzymatic Resolution of $\alpha$-acetoxysulfides: A new approach to the synthesis of homochiral S, O -Acetals, Tetrahedron Asymmetry, 1995, 6, 1903-1906. f) Milton, J.; Brand, S.; Jones, M.F.; Rayner, C.M. Enantioselective enzymatic synthesis of the anti-viral agent lamivudine (3TC ${ }^{\mathrm{TM}}$ ), Tetrahedron. Lett., 1995 36, 6961-6964. g) Cousins, R.P.C.; Mahmoudian, M.; Youds, P.M. Enzymic resolution of oxathiolane intermediates - an alternative approach to the anti-viral agent lamivudine (3TC ${ }^{\mathrm{TM}}$ ), Tetrahedron: Asymmetry, 1995, 6, 393-396. h) Jin, H.; Siddiqui, A.; Evans, C.A.; Tse, H.L.A.; Mansour, T.S.; Goodyer, M.D.; Ravenscroft, P.; Beels, C.D. Diastereoselective Synthesis of the Potent Antiviral Agent (-)-2'-Deoxy-3'-thiacytidine and Its Enantiomer, J. Org. Chem., 1995, 60, 2621-2623. i) Goodyear, M.D.; Dwyer, P.O.; Hill, M.L.; Whitehead, A.J.; Hornby, R.; Hallet, P. Process for the Diastereoselective Synthesis of Nucleoside Analogues, US6051709, 2000. j) Li, J.-Z.; Gao, L.-X.; Ding, M.-X. The Chemical Resolution of Racemic cis-2-hydroxymethyl-5-(cytosine-1'-yl)-1,3-oxathiolane (BCH-189)-One Direct method to Obtain Lamivudine as Anti-HIV and Anti-HBV Agent, Synth. Commun., 2002, 32, 2355-2359. k) Goodyear, M.D.; Hill, M.L.; West, J.P.; Whitehead, A.J. Practical enantioselective synthesis of lamivudine (3TC ${ }^{\mathrm{TM}}$ ) via a dynamic kinetic resolution, Tetrahedron Lett., 2005, 46, 8535-8538. l) Roy, B.N.; Singh, G.P.; Srivastava, D.; Jadhav, H.S.; Saini, M.B.; Aher, U.P. A Novel Method for Large-Scale Synthesis of Lamivudine through Cocrystal Formation of Racemic Lamivudine with (S)-(-)-1,1'-Bi(2-naphthol) [(S)-(BINOL)], Org. Process Res. Dev., 2009, 13, 450-455. m) Reddy, B.P.; Reddy, K.R.; Reddy, R.R.; Reddy, D.M.; Srinivas, A.S. Optical resolution of substituted 1, 3-oxathiolane nucleosides, US20110245497, 2011. n) Hu, L.; Schaufelberger, F.; Zhang, Y.; Ramström, O. Efficient asymmetric synthesis of lamivudine via enzymatic dynamic kinetic resolution, Chem. Commun., 2013, 49, 10376-10378

3) a) Nair, D.S.; Rai, B.P.; Nizar, H.; Meeran, P.N. Tewari, N. Process and intermediates for the preparation of substituted 1,3-oxathiolanes, especially lamivudine, US20100311961, 2010. b) Tewari, N.; Nair, D.S.; Nizar, H.; Meeran, P.N.; Prasad, M. Process for the preparation of substituted 1,3-oxathiolanes, US20100311970, 2010. c) Shankar, R.; Vennapureddy, R.R.; Sayyed, A.P.; Ankaraju, M.K.; Madasu, S.B.; Vascuri, J.R.; Meenakshisunderam, S. Process for preparation of cis-nucleoside derivative, US20110282046, 2011. d) Rama, S.; Gorantla, S.C.S.; Vadali, L.R.; Inupakutika, V.B.K.S.; Dasari, S.R.; Mittapelly, N.; Singh, S.K.; Datta, D. Novel process for the preparation of cis-nucleoside derivative, US20120295930, 2012. e) Roy, B.N.; Singh, G.P.; Srivastava, D.; Aher, U.P.; Patil, S.U. Stereoselective process for preparation of 1,3-oxathiolane nucleosides, US20130296562, 2013. f) Caso, M.F.; D’Alonzo, D.; D’Errico, S.; Palumbo, G.; Guaragna, A. Highly Stereoselective Synthesis of Lamivudine (3TC) and Emtricitabine (FTC) by a Novel $N$-Glycosidation Procedure, Org. Lett., 2015, 17, 2626-2629. g) Mandala, D.; Watts, P. An Improved Synthesis of Lamivudine and Emtricitabine, Chemistry Select, 2017, 2, 1102-1105. h) Aher, U.P.; Srivastava, D.; Jadhav, H.S.; Singh, G.P.; Jayashree, B.S.; Shenoy, G.G. Large-Scale Stereoselective Synthesis of 1,3-Oxathiolane Nucleoside, Lamivudine, via ZrCl4-Mediated N-Glycosylation, Org. Process Res. Dev., 2020, 24, 387-397.

4) Smit, V.A.; Zerirov, N.S.; Bodrikov, I.V.; Krimer, M.Z. Episulfonium ions: myth and reality, Acc. Chem. Res., 1979, 12, 282-288.

5) a) Martin, H.M. Manufacture of thio-acids and derivatives, US2413361, 1945. b) Coons, R.J.; Todaro, C.A. Process for producing alpha-mercapto-carboxylic acids, US2594030, 1950.

6) a) Smit, W.A.; Gromov, A.V.; Yagodkin, E.A. Adducts of ArSCl with vinyl ethers or esters as synthones in geminal alkylation, Mendeleev Commun., 2003, 13, 21-23. b) Smit, W.A.; Yagodkin, E.A.; Zatonsky, G.V. Reactions of p-toluenesulfenyl chloride with enol acetates. The synthetic potential of the resulting adducts, Russ. Chem. Bull., 2005, 54, 743-747.

7) a) Worley, J.W.; Ratts, J.W.; Cammack, K.L. 2-Dialkylphosphonyl- and 2-alkylidene-3,4-dihydro-3-oxo-2H-1,4-benzothiazines, J. Org. Chem., 1975, 40, 1731-1734. b) Pommelet, M.-C.; Nyns, C.; Lahousse, F.; Merenyi, R.; Viehe, H.G. A Novel Method of CC-Bond Formation: Thermolytic Elimination of Sulfur and Hydrogen Halides from $\alpha$-Halosulfides, Angew. Chem., Int. Ed., 1981, 20, 585-586. c) Griesbaum, K.; Scaria, P.M.; Döhling, T. Halogenated epoxides. Reaction of trans-2,3-dichlorooxirane with dimethyl sulfide, J. Org. Chem., 1986, 51, 1302-1305

8) Lauss, H.-D.; Steffens, W. "Sulfur Halides", in Ullmann's Encyclopedia of Industrial Chemistry, Weinham, Germany: WileyVCH Verlag GmbH \& Co. KGaA, 2000.

9) Rozwadowska, M.D.; Sulima, A.; Gzella, A. Synthesis, crystal structure and oxidation of (R)-(+)-8,9-dimethoxy-6,10b-dihydro5H-thiazolo[2,3-a]isoquinolin-3-one, Tetrahedron: Asymmetry, 2002, 13, 2329-2333.

10) See supporting information for complete details. 


\section{Graphical Abstract:}
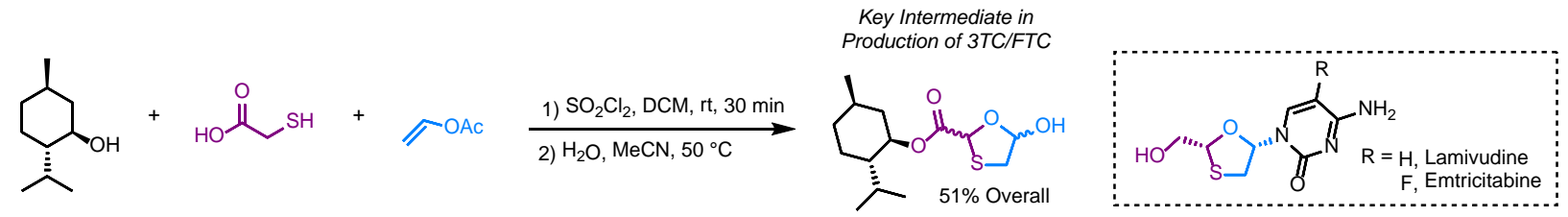